\title{
Synthesis of in,out-isomeric phosphite and phosphate cryptands
}

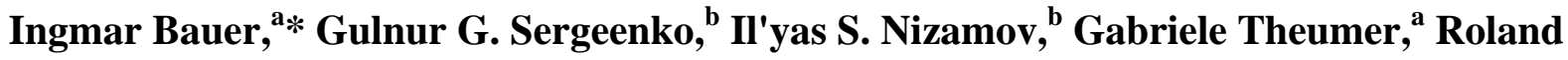 \\ Fröhlich $^{c}$, Alexander R. Burilov, ${ }^{b}$ Vera I. Maslennikova ${ }^{d}$, and Wolf D. Habicher ${ }^{a} *$ \\ ${ }^{a}$ Institute of Organic Chemistry, University of Technology Dresden, 01062 Dresden (Germany) \\ ${ }^{b}$ Arbuzov Institute of Organic and Physical Chemistry, RAS, Arbuzov str. 8, 420088 Kazan, \\ Russia \\ ${ }^{c}$ Institute of Organic Chemistry, University Münster, Corrensstrasse 40, D-48149, Münster, \\ Germany. ${ }^{d}$ Moscow Pedagogical State University, Nesvizhsky per. 3, Moscow, 119021, Russia \\ E-mail: Ingmar.Bauer@chemie.tu-dresden.de; Wolf.Habicher@chemie.tu-dresden.de
}

\section{Dedicated to Professor Alexander I. Konovalov on his $70^{\text {th }}$ birthday \\ (received 29 Oct 04; accepted 08 Jan 05; published on the web 16 Jan 05)}

\begin{abstract}
The reaction of $\mathrm{POCl}_{3}$ with the trinuclear bisphenol $\mathbf{1}$ has been investigated. All three homeomorphic in,out-isomers of the phosphorus cryptand were isolated. Among them the out,out-isomer was the main macrobicyclic product obtained. The reaction of the previously described in,in-phosphite 2 with $\mathrm{CuCl}$ afforded an interesting complex containing two metal centers bridging the cavity of the cryptand together with a central chloride ion. This complex suggested the use of $\mathrm{Cu}(\mathrm{I})$ as a template for the formation of the formerly described in,outphosphite cryptands. With this method it is now possible to carry out the reaction in higher concentrated solution to isolate larger quantities of the phosphorus macrobicycles.
\end{abstract}

Keywords: Cryptands, phosphites, phosphates, in,out-isomers, macrocycles

\section{Introduction}

Phosphorus containing cryptands are interesting molecules with potential applications in various fields of chemistry. With trivalent phosphorus incorporated into a macrobicyclic skeleton, such structures can be potential ligands for the complexation of soft metals, a feature that makes them promising candidates for selective extraction of metal cations from aqueous solution or as catalysts in transition metal catalyzed reactions such as hydroformylation, Heck reaction, Suzuki coupling and others. Pentavalent phosphoryl compounds are interesting for complexation and separation of lanthanides and actinides. The macrocyclic framework can support the complexation and selectivity by either providing the appropriate size for a specific metal or 
additional cooperative functions such as $\pi$-donating aromatic moieties. Both types of phosphorus compounds can also play an important role in supra-molecular chemistry for molecular recognition of charged and neutral organic substrates especially also for those of biological interest. Despite of their interesting properties the number of phosphorus containing macrocycles and macrobicycles is, contrary to their aza analogues, still limited but has continuously grown during the last two/three decades. ${ }^{1}$ If the phosphorus occupies bridgehead positions, in,outisomers regarding the position of the exocyclic rest at the phosphorus in respect to the cavity, are possible. The phenomenon of in,out-isomerism has been summarized by Alder. ${ }^{2}$ A review on in,out-isomerism of phosphorus bridgehead compounds is also available. ${ }^{3}$ Especially in-groups might be interesting as their exceptional position inside the cavity provides a defined micro environment which can pronouncedly differ from the bulk solution and which can be predicted as the macrobicyclic framework is relatively rigid and has less degrees of freedom than open chain skeletons. So far, only a small number of stable in-isomers has been isolated. Bridging atoms therein have mainly been methines, ${ }^{4}$ amines and ammonium ${ }^{5}$ ions and in very few cases phosphorus atoms. ${ }^{6}$ Largest in-group reported so far is a methyl group at a $\mathrm{sp}^{3}$-C-bridgehead centre by Vögtle and coworkers. ${ }^{7}$ We were able to successfully employ a double-capping method for the synthesis of the out,out- and in,out-isomers of a sterical hindered, flexible phosphorus containing cryptand. ${ }^{8}$ Reacting two non-hindered bisphenols with $\mathrm{PCl}_{3}$ each, we could even isolate all three homeomorphic isomers of the corresponding phosphite cage compounds in reasonable yields. ${ }^{9}$ The corresponding phosphate cryptands have been observed but not isolated in most cases by treating the phosphite cryptands with cumene hydroperoxide. In-positions are therein much less reactive than out-phosphites. It was interesting to see whether the corresponding in,out-phosphates and in,out-thiophosphates can be obtained directly by the same double-capping method as employed for the phosphite cryptands. The product distribution of the corresponding in,out-isomers will be discussed in the present paper.

\section{Results and Discussion}

The double-capping reaction of $\mathrm{PCl}_{3}$ with bisphenol 1, we reported earlier, required rather diluted conditions $\left(5 \times 10^{-3} \mathrm{~mol} / 1\right.$ of the bisphenol) to obtain $12 \%$ of a mixture of all three homeomorphic isomers. ${ }^{9 a}$ It seems obvious to study a templated version of this reaction to improve the yield of the cryptands and in particular those of in,in-phosphite 2. As $\mathrm{Cu}(\mathrm{I})$ ions should be readily complexed with phosphite functions, we reacted in,in-phosphite 2 with $\mathrm{CuCl}$ to investigate the structure of such complexes. A solution of $\mathrm{CuCl}$ in moist $\mathrm{CH}_{3} \mathrm{CN}$ was slowly added to a toluene solution of the cryptand. After a few minutes crystals separated at the phase interface. They have been investigated by ${ }^{31} \mathrm{P},{ }^{1} \mathrm{H},{ }^{13} \mathrm{C}$ NMR, MALDI TOF MS and elemental analysis. However, we were not able to obtain an X-ray structure of them so that we can only tentatively assign structure 3 to them (Scheme 1). It shows an interesting complex cation of the in,in-macrobicyclic framework with two $\mathrm{Cu}(\mathrm{I})$ centers and a central chloride atom. These three 
atoms form a fourth bridge between the phosphorus bridgeheads of the ligand through the inside of the cavity. The structure is topologically reminiscent of a propellane compound. It formally represents a type of ligand stabilized $\left[\mathrm{Cu}_{2} \mathrm{Cl}\right]^{+}$cation.

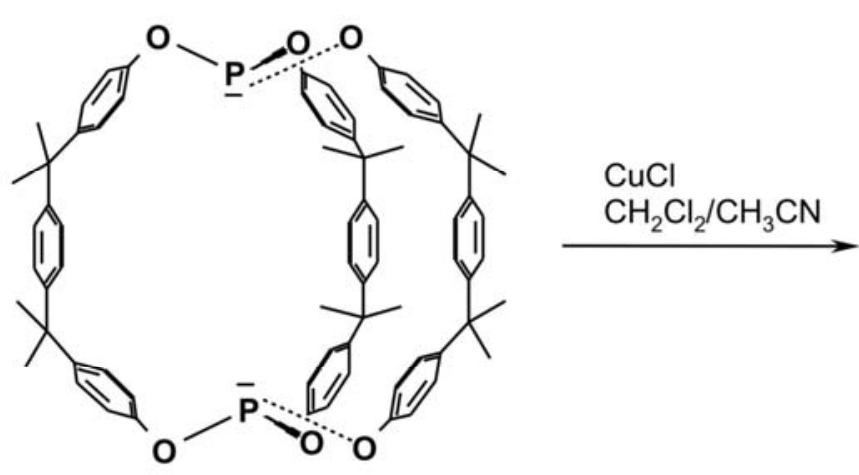

2

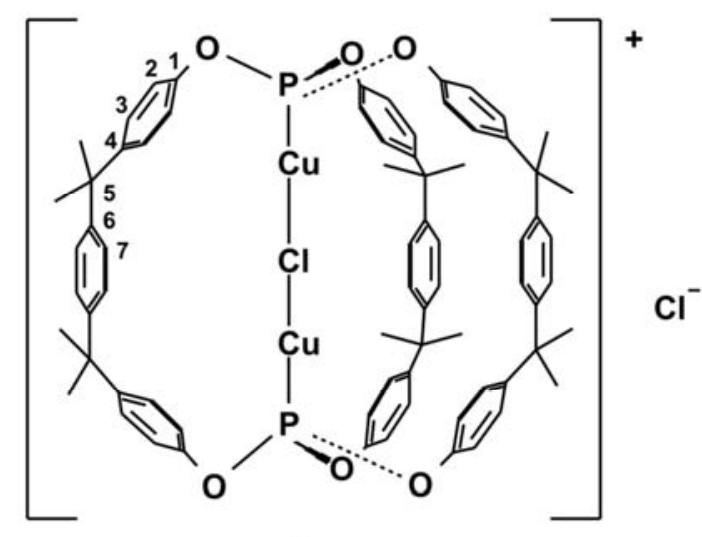

3

\section{Scheme 1}

The ${ }^{31} \mathrm{P}$ NMR spectrum of 3 shows a broad peak at $112.1 \mathrm{ppm}$ which is in accordance with ${ }^{31} \mathrm{P}$ NMR shifts for other P-Cu complexes. ${ }^{10}$ Its ${ }^{1} \mathrm{H}$ and ${ }^{13} \mathrm{C}$ NMR spectra are very simple and reflect the $C_{3 \mathrm{v}}$ symmetry of the molecule. Most convincing, however, is the MALDI TOF peak at $1258 \mathrm{Da}$ for the complex cation. An exact elemental analysis for the proposed compound was achieved. With these data in mind we expected a favorable template effect for the reaction of $\mathrm{PCl}_{3}$ with bisphenol 1 in the presence of $\mathrm{CuCl}$ to form larger quantities of in,in-phosphite 2 compared to the non-templated reaction reported by us earlier. ${ }^{9 a}$ The reaction was accordingly carried out in toluene in the presence of triethylamine and $\mathrm{CuCl}$, but with a one order of magnitude higher concentration of the educts compared to the previously reported reaction. The initially formed amino $\mathrm{Cu}(\mathrm{I})$ complex is destroyed in the course of the reaction as the amine is protonated by $\mathrm{HCl}$ released from the esterification reaction. Instead a phosphite $\mathrm{Cu}(\mathrm{I})$ complex is formed as was observed by following the reaction by ${ }^{31} \mathrm{P}$ NMR giving a broad peak at $110 \mathrm{ppm}$. The crude product of the reaction was washed with ammonia solution to decompose the complex. The finally obtained product mixture after filtration through silica with toluene/ $\mathrm{CH}_{2} \mathrm{Cl}_{2}$ is in terms of ratio of homeomorphic in,out-isomers more or less identical with those of the nontemplated reaction. Enrichment of in,in-product 2 was not achieved. However, the yield does not dramatically decrease when the reaction solution is more concentrated as was observed for the non-templated reaction. In fact even a concentration of $3 \times 10^{-2} \mathrm{~mol} / 1$ of the bisphenol $\mathbf{1}$, one order of magnitude higher than for the non-templated reaction, still led to yields of $6.6 \%$ for the total of all phosphorus cryptand isomers, which allowed us to isolate about half a gram of out,out-isomer $\mathbf{4}$ and in,out-isomer $\mathbf{5}$ and $200 \mathrm{mg}$ of in,in-isomer $\mathbf{2}$ in one batch (Scheme 2). The analytical data for compounds $2, \mathbf{4}$ and $\mathbf{5}$ are in agreement with those described by us earlier. ${ }^{9 \mathrm{a}}$ 


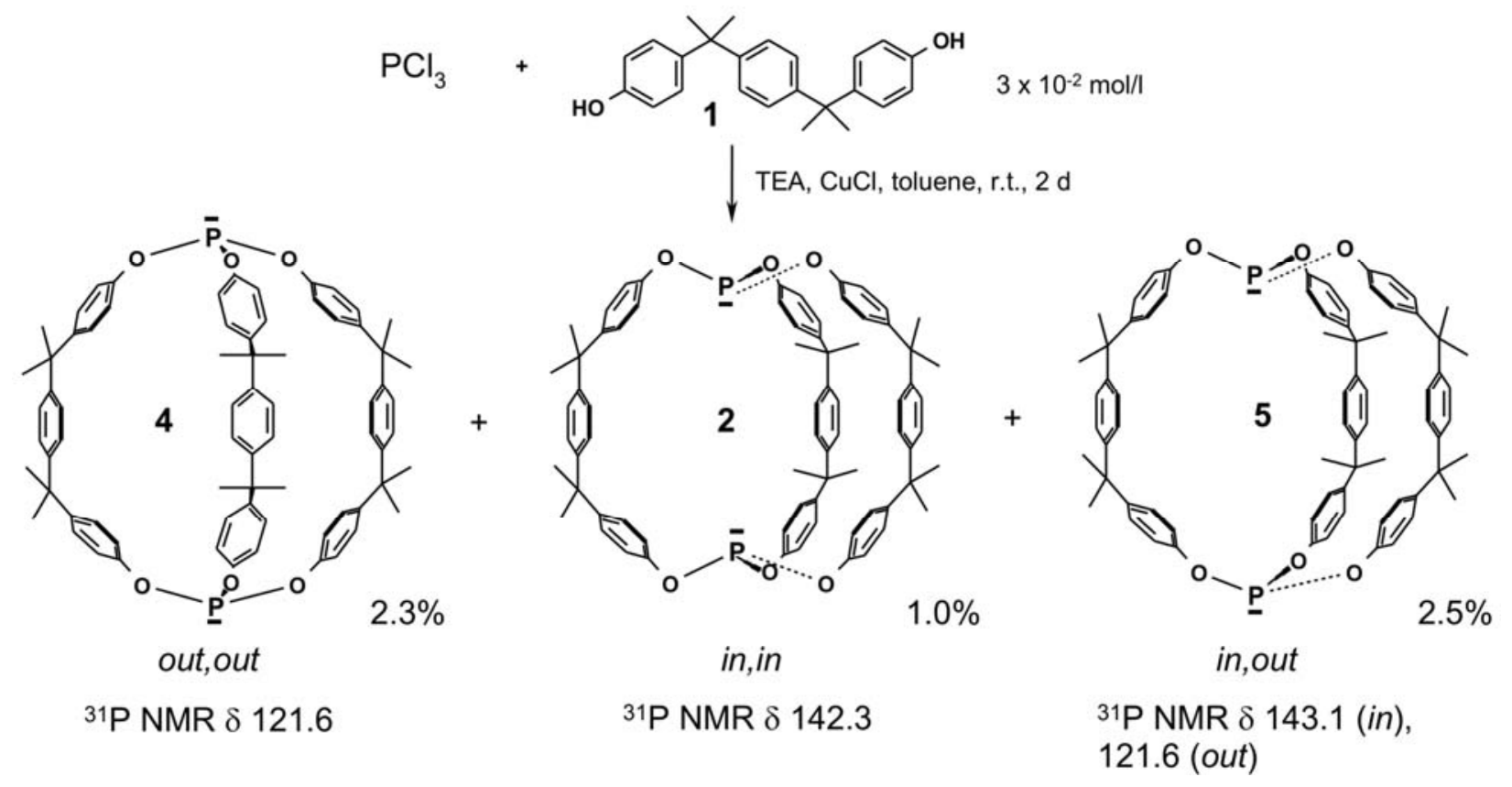

\section{Scheme 2}

In order to obtain the corresponding phosphate cryptands, the reaction of $\mathrm{POCl}_{3}$ with bisphenol 1 was carried out in toluene in the presence of triethyl amine. After stirring for 3 days at room temperature a product mixture containing all three homeomorphic in,out-isomers was obtained. A subsequent column chromatography on silica gel with $\mathrm{CH}_{2} \mathrm{Cl}_{2} / \mathrm{EtOAc}$ (40:1) afforded the three isomers in a pure state. The main cryptand obtained was the out,out-isomer 6 with $14 \%$ yield followed by the in,out-isomer 7 with $5.6 \%$ and in,in-isomer 8 which could be obtained only in $1.6 \%$ yield (Scheme 3 ).

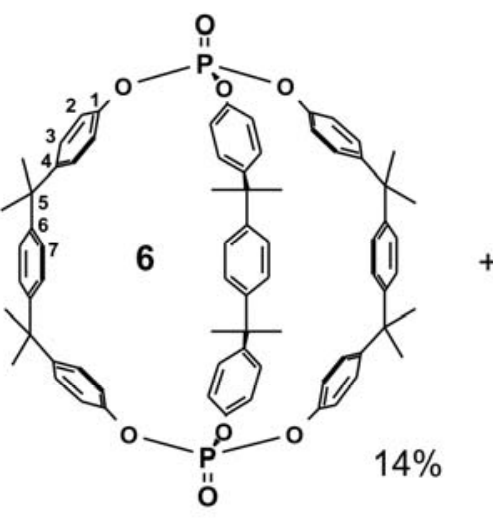

out,out

${ }^{31}$ P NMR $\delta-19.4$
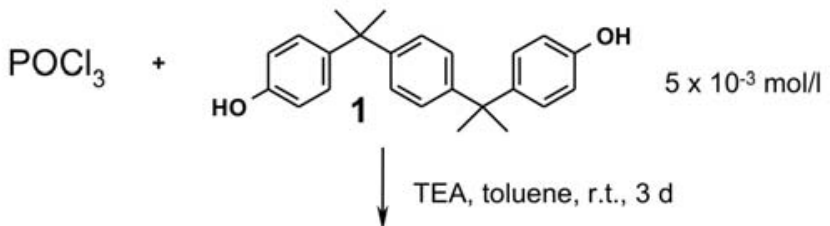

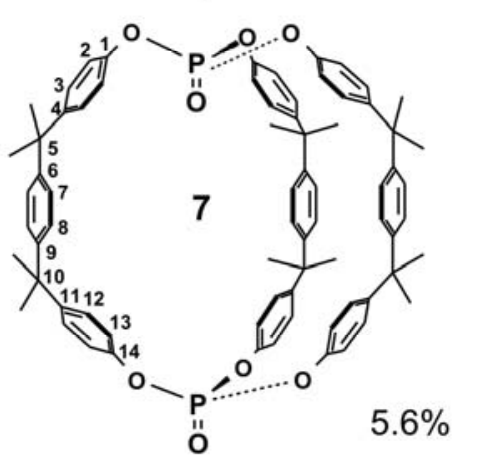

in,out

${ }^{31} \mathrm{P}$ NMR $\delta-11.5$ (in), -19.8 (out)

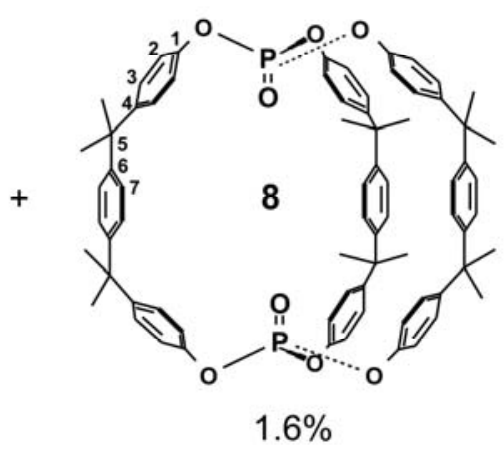

in, in

${ }^{31} \mathrm{P}$ NMR $\delta-12.7$

\section{Scheme 3}


All isomers have been characterized by ${ }^{31} \mathrm{P},{ }^{1} \mathrm{H}$ and ${ }^{13} \mathrm{C}$ NMR, MALDI-TOF $\mathrm{MS}$ and elemental analysis. All of them have melting points higher than $360^{\circ} \mathrm{C}$. In,in-isomer 8 has already been described by us earlier by oxidation of in,in-phosphite 2 with cumene hydroperoxide. The ${ }^{31} \mathrm{P}$ NMR shifts of $\mathbf{6}$ and $\mathbf{7}$ have also been reported therein, without isolation of the corresponding products. ${ }^{9 a}$ The ${ }^{31} \mathrm{P}$ NMR chemical shifts for in- and out-positions are different but not as pronounced as for the corresponding phosphites. Again the signals for the inphosphorus atoms are shifted to low field, namely $-11.5 \mathrm{ppm}$ for in,out-compound 7 and -12.7 ppm for in,in-cryptand 8. The chemical shifts for the out-positions are more or less in a region where open chain aryl phosphates would be expected, in particular -19.4 ppm for out,outcompound 6 and -19.8 ppm for in,out-cryptand 7. The ${ }^{1} \mathrm{H}$ and ${ }^{13} \mathrm{C}$ NMR spectra reflect the high symmetry of the products in solution. Out,out-compound $\mathbf{6}$ and in,in-compound 8 have $C_{3 \mathrm{v}}$ symmetry. Both halves of the molecule are magnetically equivalent which leads to a single ${ }^{31} \mathrm{P}$ NMR peak for each of them and very simple ${ }^{1} \mathrm{H}$ and ${ }^{13} \mathrm{C}$ spectra. In,out-compound 7 is only $C_{3}$ symmetric giving different signals for corresponding atoms on the two sides of the molecule.

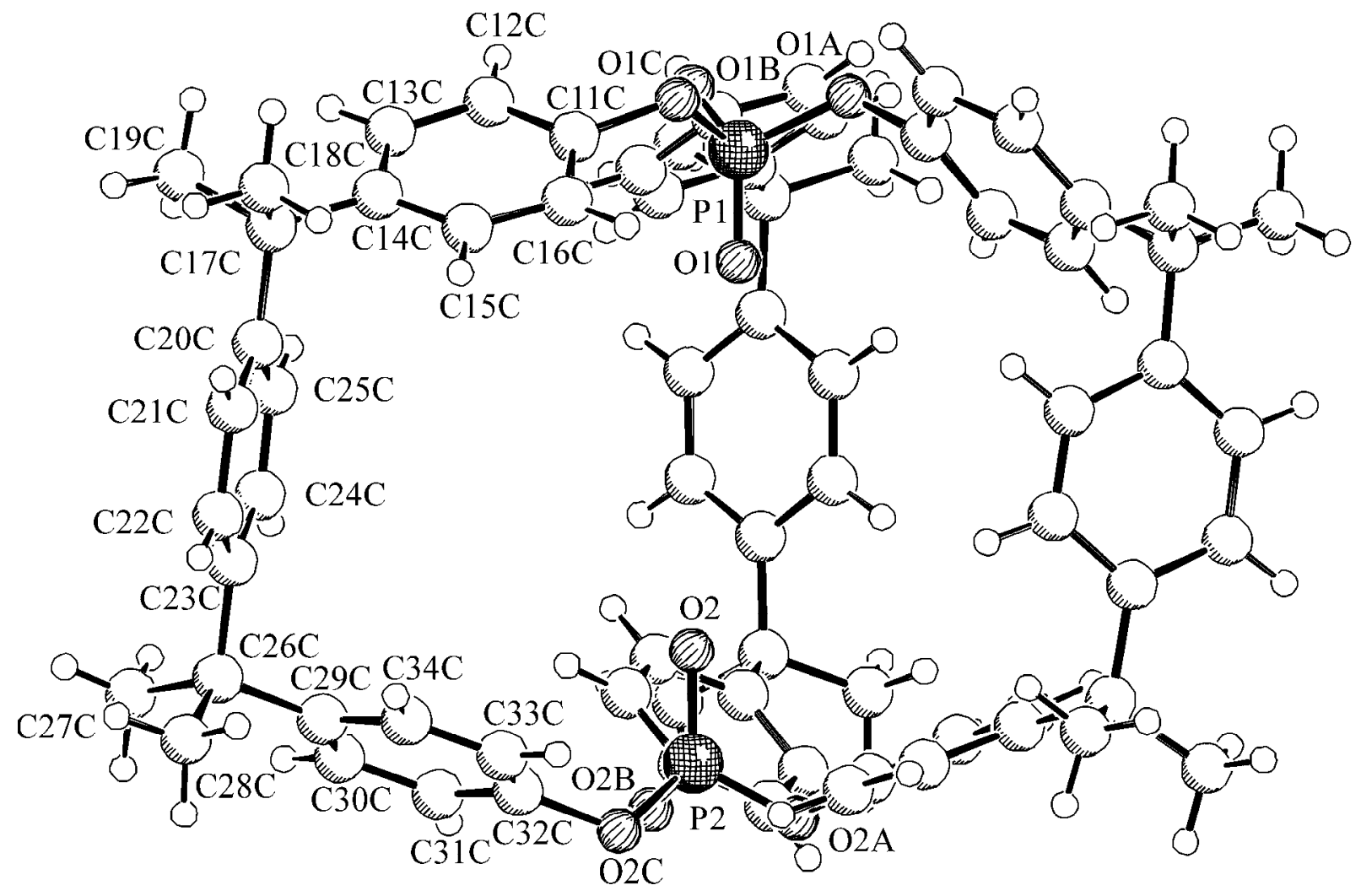

Figure 1

We were able to grow crystals of in,in-phosphate 8 from $\mathrm{CH}_{2} \mathrm{Cl}_{2} / \mathrm{CH}_{3} \mathrm{CN}$. The X-ray structure of it is presented in Figure 1. However, the small size of the crystals and a high content of solvent molecules leading to a low diffracting power, allows us only to confirm the in,in- 
phosphate structure but not to discuss geometrical details. The crystal contains a large number of solvent molecules namely one molecule of $\mathrm{CH}_{2} \mathrm{Cl}_{2}$, four molecules of $\mathrm{CH}_{3} \mathrm{CN}$ and half a molecule of hexane per unit cell, which are located both inside and outside the cavity. The solvent molecules have been omitted in Figure 1 for clarity. The distance between the two inoxygen atoms is approximately $5 \AA$.

In summary, application of $\mathrm{POCl}_{3}$ compared to $\mathrm{PCl}_{3}$ in the double-capping reaction with bisphenol 1 leads to a higher fraction of the out,out-isomer in comparison to the in,in-isomer. This can be attributed to the higher sterical demand of the phosphoryl oxygen in the in-position. It will be interesting to investigate whether the corresponding reaction with $\mathrm{PSCl}_{3}$ continues this trend and probably does not form the in,in-isomer at all. However, it is possible to place two sulfur atoms inside the cavity as the in,in-thiophosphate cryptand has already been described by us as a side product of a Staudinger reaction of in,in-phosphite 2 with a thiophosphoryl azide. ${ }^{11}$

\section{Experimental Section}

General Procedures. The melting points were determined on a Boëtius melting point apparatus. ${ }^{1} \mathrm{H}$ NMR (TMS internal reference), ${ }^{13} \mathrm{C}$ NMR (TMS internal reference) and ${ }^{31} \mathrm{P}$ NMR spectra (85\% $\mathrm{H}_{3} \mathrm{PO}_{4}$ external reference) were recorded on Bruker AC-300 and DRX-500 spectrometers. MALDI-TOF mass spectra were measured on a Kratos Kompact MALDI II (Shimadzu Europa $\mathrm{GmbH}$, Duisburg, Germany) using a $\mathrm{N}_{2}$-laser source $(\lambda=337 \mathrm{~nm})$, a positive polarity and $20 \mathrm{kV}$ acceleration voltage. The microanalyses were recorded on a CHN-S analyzer (Carlo Erba). Solvents were purified by conventional methods.

Cu(I)-complex (3). To a solution of $50 \mathrm{mg}$ of in,in-phosphite $2(0.046 \mathrm{mmol})$ in $5 \mathrm{ml}$ of $\mathrm{CH}_{2} \mathrm{Cl}_{2}$ was slowly added a solution of $9 \mathrm{mg}(0.091 \mathrm{mmol})$ of $\mathrm{CuCl}$ in moist $\mathrm{CH}_{3} \mathrm{CN}$. After a short period of about $30 \mathrm{~min}$, crystals of 3 precipitated and were separated by filtration; Yield: $39 \mathrm{mg}$ (65\%), decomp. $\sim 360^{\circ} \mathrm{C} ;{ }^{31} \mathrm{P}$ NMR $\left(121.5 \mathrm{MHz}, \mathrm{CDCl}_{3}\right)$ : $\delta=112.1$ (br.); ${ }^{1} \mathrm{H} \mathrm{NMR}(300.1 \mathrm{MHz}$, $\left.\mathrm{CDCl}_{3}\right): \delta 7.06\left(2 \mathrm{~d}^{*}, 24 \mathrm{H}, 2,3-\mathrm{H}\right), 7.01(\mathrm{~s}, 12 \mathrm{H}, 7-\mathrm{H}), 1.65(\mathrm{~s}, 36 \mathrm{H}, 5-\mathrm{Me}) ;{ }^{13} \mathrm{C} \mathrm{NMR}(75.5 \mathrm{MHz}$, $\left.\mathrm{CDCl}_{3}\right): \delta=148.4(\mathrm{C}-1)^{\#}, 147.7(\mathrm{C}-6){ }^{\#}, 147.2(\mathrm{C}-4){ }^{\#}, 128.2(\mathrm{C}-3)^{\dagger}, 126.2(\mathrm{C}-7)^{\dagger}, 120.2$ (d, $\left.{ }^{3} J(\mathrm{P}, \mathrm{C})=6.2 \mathrm{~Hz}, \mathrm{C}-2\right), 42.0$ (C-5), 29.9 (5-Me); MALDI-TOF-MS (matrix: 1,8,9-trihydroxyanthracene): $\mathrm{m} / \mathrm{z}: 1258\left[\mathrm{M}-\mathrm{Cl}^{-}\right]^{+}$; elemental analysis calcd (\%) for $\mathrm{C}_{72} \mathrm{H}_{72} \mathrm{O}_{6} \mathrm{P}_{2} \mathrm{Cu}_{2} \mathrm{Cl}_{2}$ (1293.23): C 66.87, H 5.61, Cl 5.48; found C 66.64, H 5.64, Cl 5.95.

* Coupling constant not determined, because signals are very close together to appear as one singlet.

$\#, \dagger$ Signals assigned in accordance with those of in,in-phosphite $2,{ }^{9 a}$ which have been proven by various 2D NMR techniques including ${ }^{1} \mathrm{H} /{ }^{31} \mathrm{P}$ correlated $\mathrm{HMBC}$ and ${ }^{31} \mathrm{P} /{ }^{1} \mathrm{H}$ correlated HOESY.

Reaction of 1 with $\mathbf{P C l}_{3}$ in the presence of CuCl. Biphenol 1 (20.0 g, $57.7 \mathrm{mmol}$ ) and TEA $(15.0 \mathrm{~g}, 148.2 \mathrm{mmol})$ were dissolved in toluene $(2.0 \mathrm{~L})$ in a flame-dried $2 \mathrm{~L}$ flask under argon atmosphere (1 is only partly soluble). Anhydrous $\mathrm{CuCl}(3.8 \mathrm{~g}, 38.4 \mathrm{mmol})$ was added and the 
solution was stirred at room temperature for $10 \mathrm{~min}$. Under vigorous stirring $\mathrm{PCl}_{3}(5.3 \mathrm{~g}, 38.6$ mmol) was added dropwise by syringe within $10 \mathrm{~min}$. The solution was stirred for $2 \mathrm{~d}$ at $25^{\circ} \mathrm{C}$. The hydrochloride formed was removed by filtration and the solvent was concentrated in vacuum to $400 \mathrm{ml}$. Subsequently it was washed three times with $40 \mathrm{ml}$ concentrated ammonia solution each until the color of the washing solution did not turn blue. After the first washing procedure a white solid precipitated which was filtered and disposed. The organic layer was dried over $\mathrm{MgSO}_{4}$ and further concentrated to $40 \mathrm{ml}$. Subsequently it was filtered through silica gel with toluene/ $\mathrm{CH}_{2} \mathrm{Cl}_{2}(4: 1)$ as eluent. After evaporation of the solvent mixture $1.40 \mathrm{~g}(6.6 \%)$ of a white solid were obtained, which contained a mixture of the three homeomorphic isomers 2 , 4 and 5. They could be separated by column chromatography on silica gel with cyclohexane/toluene (2:1) to afford out,out-macrobicycle 4 (480 mg, 2.3\%, compound partly hydrolyzes on the column), in,out-phosphite 5 (530 mg, 2.5\%) and in,in-phosphite 2 (210 mg, $1.0 \%$,), as white solids. The analytical data of 2,4 and 5 are in accordance with those described in the literature. ${ }^{9 \mathrm{a}}$

Reaction of 1 with $\mathbf{P O C l}_{3}$. Biphenol 1 (1.00 g, $\left.2.9 \mathrm{mmol}\right)$ and TEA (0.75 g, $\left.7.4 \mathrm{mmol}\right)$ were dissolved in toluene $(500 \mathrm{~mL})$ in a flame-dried $1 \mathrm{~L}$ flask under argon atmosphere $(\mathbf{1}$ is only partly soluble). Under vigorous stirring $\mathrm{POCl}_{3}(0.30 \mathrm{~g}, 1.95 \mathrm{mmol})$ was added dropwise by syringe within $10 \mathrm{~min}$. The solution was stirred for $3 \mathrm{~d}$ at $25^{\circ} \mathrm{C}$. The hydrochloride formed was removed by filtration and the solvent was evaporated in vacuum to yield a viscous oil containing a mixture of 6, 7, and 8 and some non-cyclic and simple macrocyclic byproducts according to ${ }^{31} \mathrm{P}$ NMR. Chromatography on silica gel with $\mathrm{CH}_{2} \mathrm{Cl}_{2} /$ EtOAc (40:1) afforded out,out-macrobicycle 6 (152 mg, 14.0\%), in,out-phosphate 7 (61 mg, 5.6\%) and in,in-phosphate $8^{9 \mathrm{a}}(17 \mathrm{mg}, 1.6 \%)$ as white solids.

Out,out-phosphate (6). m.p. $>360{ }^{\circ} \mathrm{C} ;{ }^{31} \mathrm{P}$ NMR (121.5 MHz, $\left.\mathrm{CDCl}_{3}\right): \delta=-19.3 ;{ }^{1} \mathrm{H}$ NMR $(300.1$ $\left.\mathrm{MHz}, \mathrm{CDCl}_{3}\right): \delta 7.13\left(\mathrm{~d},{ }^{3} \mathrm{~J}(\mathrm{H}, \mathrm{H})=8.8 \mathrm{~Hz}, 12 \mathrm{H}, 2-\mathrm{H}\right), 7.06(\mathrm{~s}, 12 \mathrm{H}, 7-\mathrm{H}), 7.05\left(\mathrm{~d},{ }^{3} J(\mathrm{H}, \mathrm{H})=8.5\right.$ $\mathrm{Hz}, 12 \mathrm{H}, 3-\mathrm{H}), 1.64$ (s, 36H, 5-Me); ${ }^{13} \mathrm{C} \mathrm{NMR}\left(75.5 \mathrm{MHz}, \mathrm{CDCl}_{3}\right): \delta=148.3\left(\mathrm{~d},{ }^{2} J(\mathrm{P}, \mathrm{C})=8.7\right.$ $\mathrm{Hz}, \mathrm{C}-1), 148.1,147.4$ (C-4, C-6), 129.2, 127.1 (C-3, C-7), 119.2 (d, $\left.{ }^{3} J(\mathrm{P}, \mathrm{C})=4.6 \mathrm{~Hz}, \mathrm{C}-2\right), 42.2$ (C-5), 29.7 (5-Me); MALDI-TOF-MS (matrix: 1,8,9-trihydroxyanthracene): $\mathrm{m} / \mathrm{z}: 1128[\mathrm{M}+\mathrm{H}]^{+}$; elemental analysis calcd (\%) for $\mathrm{C}_{72} \mathrm{H}_{72} \mathrm{O}_{8} \mathrm{P}_{2}$ (1127.28): C 76.71, H 6.44; found C 76.38, H 6.67.

In,out-phosphate (7). m.p. $>360^{\circ} \mathrm{C} ;{ }^{31} \mathrm{P} \mathrm{NMR}\left(121.5 \mathrm{MHz}, \mathrm{CDCl}_{3}\right.$ ): $\delta=-11.5$ (in), -19.6 (out); ${ }^{1} \mathrm{H}$ NMR (300.1 MHz, $\left.\mathrm{CDCl}_{3}\right): \delta$ 7.20-7.07 (m, 24H, 2,3,12,13-H), 7.03 (s, 12H, 7,8-H), 1.65, 1.60 (s, 18H each, 5,10-Me); ${ }^{13} \mathrm{C}$ NMR (75.5 MHz, $\left.\mathrm{CDCl}_{3}\right): \delta=148.4\left(\mathrm{~d},{ }^{2} J(\mathrm{P}, \mathrm{C})=8.6 \mathrm{~Hz}, \mathrm{C}-1\right.$ or C-14), $148.3\left(\mathrm{~d},{ }^{2} J(\mathrm{P}, \mathrm{C})=6.2 \mathrm{~Hz}, \mathrm{C}-1\right.$ or C-14), 148.0, 147.6, 147.4, 147.3 (C-4, C-11, C-6, C-9), 128.12, 128.10 (C-3, C-12), 126.3, 126.2 (C-8, C-7), 119.6 (d, ${ }^{3} J(\mathrm{P}, \mathrm{C})=4.7 \mathrm{~Hz}, \mathrm{C}-13$ or C-2), $119.2\left(\mathrm{~d},{ }^{3} J(\mathrm{P}, \mathrm{C})=4.7 \mathrm{~Hz}, \mathrm{C}-13\right.$ or C-2), 42.2, 42.0 (C-5, C-10), 30.8, 30.3 (5-Me, 10$\mathrm{Me}$ ); MALDI-TOF-MS (matrix: 1,8,9-trihydroxyanthracene): $\mathrm{m} / \mathrm{z}: 1128[\mathrm{M}+\mathrm{H}]^{+}$; elemental analysis calcd (\%) for $\mathrm{C}_{72} \mathrm{H}_{72} \mathrm{O}_{8} \mathrm{P}_{2}$ (1127.28): C 76.71, H 6.44; found C 76.22, H 6.72.

In, in-phosphate (8). Analytical data are in agreement with those in the literature. ${ }^{9 \mathrm{a}}$

Crystal data for 8. formula $\mathrm{C}_{72} \mathrm{H}_{72} \mathrm{O}_{8} \mathrm{P}_{2} * 4 \mathrm{C}_{2} \mathrm{H}_{3} \mathrm{~N} * \mathrm{CH}_{2} \mathrm{Cl}_{2} * 0.5 \mathrm{C}_{6} \mathrm{H}_{14}, M=1419.46$, colorless crystal $0.20 \times 0.15 \times 0.05 \mathrm{~mm}, a=16.016(1), b=16.085(1), c=18.422(1) \AA, \alpha=$ 
71.00(1), $\beta=64.44(1), \gamma=75.40(1), V=4015.8(4) \AA^{3}, \rho_{\text {calc }}=1.174 \mathrm{~g} \mathrm{~cm}^{-3}, \mu=1.76 \mathrm{~cm}^{-1}$, no absorption correction ( $0.966 \leq T \leq 0.991), Z=2$, triclinic, space group $P 1$ bar (No. 2), $\lambda=0.71073$ $\AA, T=198 \mathrm{~K}, \omega$ and $\varphi$ scans, 16867 reflections collected $( \pm h, \pm k, \pm l),[(\sin \theta) / \lambda]=0.54 \AA^{-1}, 10441$ independent $\left(R_{\text {int }}=0.066\right)$ and 5849 observed reflections $[I \geq 2 \sigma(I)], 828$ refined parameters, $R$ $=0.160, w R^{2}=0.381$, max. residual electron density $1.31(-0.9)$ e $\AA^{-3}$, hydrogen atoms calculated and refined as riding atoms. Structure analysis was only done to prove the presence of the in,inisomer. Due to the small crystal size and the high content of solvent molecules the diffracting power is very low. Even a long data-collection time with the generator at highest possible power resulted in data set only usable up to $2 \theta$ of $45^{\circ}$. All solvent molecules are refined with isotropic thermal parameters only, disorder could not be refined due to the limited amount of observed reflections. Three of the four acetonitriles are refined with the first one as a geometrical model (SAME instruction). The remaining electron density could not be assigned in chemical meaningful way. Data set was collected with a Nonius Kappa CCD diffractometer, equipped with a rotating anode generator Nonius FR591. Programs used: data collection COLLECT (Nonius B.V., 1998), data reduction Denzo-SMN, ${ }^{12}$ structure solution SHELXS-97, ${ }^{13}$ structure refinement SHELXL-97 (G.M. Sheldrick, Universität Göttingen, 1997), graphics SCHAKAL (E. Keller, 1997).

\section{Supplementary Information}

Crystallographic data (excluding structure factors) for structure $\mathbf{8}$ reported in this paper have been deposited with the Cambridge Crystallographic Data Centre as supplementary publication CCDC-251947. Copies of the data can be obtained free of charge on application to The Director, CCDC, 12 Union Road, Cambridge CB2 1EZ, UK [fax: int. code +44(1223)336-033, e-mail: deposit@ccdc.cam.ac.uk].

\section{Acknowledgements}

The financial support of this work by the BMBF (RUS 00/216, RUS 02/034) is gratefully acknowledged.

\section{References and Footnotes}

1. (a) Caminade, A.-M.; Majoral, J.-P. Chem. Rev. 1994, 94, 1183. (b) Caminade, A.-M.; Kraemer, R.; Majoral, J.-P. New J. Chem. 1997, 21, 627. (c) Dutasta, J. P. Top. Curr. Chem. 2004, 232, 55.

2. Alder, R. W.; East, S. P. Chem. Rev. 1996, 96, 2097. 
3. Bauer, I.; Habicher, W. D. Collect. Czech. Chem. Commun. 2004, 69, 1195.

4. For a new example see: Bucher, C.; Zimmerman, R. S.; Lynch, V.; Sessler, J. L. Chem. Commun. 2003, 1646.

5. (a) Vögtle, F. Cyclophan-Chemie; Teubner Studienbücher Chemie: Stuttgart, 1990. (b) Vögtle, F. Supramolekulare Chemie; Teubner Studienbücher Chemie: Stuttgart, 1992. (c) Dietrich, B.; Viout, P.; Lehn, J.-M. Macrocyclic Chemistry: Aspects of Organic and Inorganic Supramolecular Chemistry; VCH: Weinheim, New York, Basel, Cambridge, 1992. (d) Schneider, H.-J.; Yatsimirski, A. K. Principles and Methods in Supramolecular Chemistry; Wiley: Chichester, 1999. (e) Steed, J. W.; Atwood, J. L. Supramolecular Chemistry; Wiley: Chichester, 2000.

6. (a) Friedrichsen, B. P.; Whitlock, H. W. J. Am. Chem. Soc. 1989, 111, 9132.(b) Friedrichsen, B. P.; Powell, D. R.; Whitlock, H. W. J. Am. Chem. Soc. 1990, 112, 8931.

7. (a) Franke, J.; Vögtle, F. Angew. Chem. 1985, 97, 224; Angew. Chem. Int. Ed. Engl. 1985, 24, 219. (b) Wallon, A.; Peter-Katalinic, J.; Werner, U.; Müller, W. M.; Vögtle, F. Chem. Ber. 1990, 123, 375. (c) Seel, C.; Vögtle, F. Angew. Chem. 1992, 104, 542; Angew. Chem., Int. Ed. 1992, 31, 528.

8. Bauer, I.; Habicher, W.D. Phosphorus, Sulfur Silicon Relat. Elem. 1997, 130, 89.

9. (a) Bauer, I.; Rademacher, O.; Gruner, M.; Habicher, W. D. Chem. Eur. J. 2000, 6, 3043. (b) Bauer, I.; Fröhlich, R.; Ziganshina, A.; Prosvirkin, A.; Gruner, M.; Habicher, W. D. Chem. Eur. J. 2002, 8, 5622.

10. Sakhaii, P.; Neda, I.; Freytag, M.; Thönnessen, H.; Jones, P. G.; Schmutzler, R. Z. Allg. Anorg. Chem. 2000, 626, 1246.

11. Bauer, I.; Gruner. M.; Goutal, S.; Habicher, W. D. Chem. Eur. J. 2004, 10, 4011.

12. Otwinowski, Z.; Minor, W. Methods in Enzymology 1997, 276, 307.

13. Sheldrick, G. M. Acta Cryst. 1990, A46, 467. 